\title{
Peels of Citrus Fruits: A Potential Source of Anti-inflammatory and Anti-nociceptive Agents
}

\author{
Pallavi Malleshappa', Ramesh Chapeyil Kumarann ${ }^{1,}$, Krishna Venkatarangaiah ${ }^{2}$, Sameera Parveen ${ }^{1}$
}

\section{Pallavi Malleshappa', Ramesh Chapeyil Kumaran ${ }^{1, *}$, Krishna Venkatarangaiah ${ }^{2}$, Sameera Parveen ${ }^{1}$}

'Department of PG studies and Research in Biotechnology, Sahyadri Science College, Kuvempu University, Shimoga - 577 203, Karnataka, INDIA. ${ }^{2} P G$ Department of Studies and Research in Biotechnology, Kuvempu University, Jnana Sahyadri, Shankaraghatta - 577 451, Shimoga, Karnataka, INDIA.

Correspondence

Dr. Ramesh Chapeyil Kumaran

Department of PG Studies and Researching Biotechnology, Sahyadri Science College, Kuvempu University, Shimoga - 577 203, Karnataka, INDIA

Phone no : +91 9972257989

E-mail: ckramck@gmail.com

History

- Submission Date: 03-05-2018;

- Review completed: 28-06-2018

- Accepted Date: 11-07-2018

DOI : 10.5530/pj.2018.6s.30

Article Available online

http://www.phcogj.com/v10/i6s

Copyright

(C) 2018 Phcog.Net. This is an openaccess article distributed under the terms of the Creative Commons Attribution 4.0 International license.

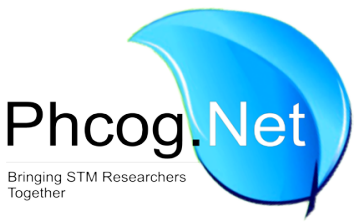

\begin{abstract}
Introduction: The present study was contemplated to evaluate the anti-inflammatory and analgesic potentials in peels of some commercially grown Citrus fruits of South India viz, Lime (Citrus aurantifolia), Orange (Citrus reticulata), Sour Orange (Citrus aurantium), Pomello (Citrus grandis) and Citron (Citrus medica). Methods: The peel of the fruits were separated and subjected to cold extraction using $70 \%$ alcohol. The extracts obtained were screened for the presence of phytoconstituents by qualitative phytochemical analysis; the anti-inflammatory activity of extracts at 250 and $500 \mathrm{mg} / \mathrm{Kg}$ body weight concentrations were assessed by in vivo Carrageenan induced rat paw edema model and in vitro HRBC membrane stabilization assay whereas Tail immersion and Hot plate methods have been used to evaluate their analgesic property. Results: The results revealed that, all extracts treated animals have shown significant decrease in paw edema volume at $3^{\text {rd }}$ and $4^{\text {th }}$ hour of treatment and increase in reaction time in tail immersion and hot plate readings at 120 and $150 \mathrm{~min}$ and are comparable to the standards. From the results it was evident that Citron peel extract exhibited significant antiinflammatory and analgesic property in all models. Preliminary phytochemical investigation revealed that extracts were bestowed with presence of flavonoids, terpenoids, steroids, glycosides, alkaloids, carotenoids and phenolic compounds which might be responsible for the antinociceptive and anti-inflammatory activities. Conclusion: From the results it was evident that all citrus fruits have prominent activity in terms of parameters assessed in a dose dependent manner and are more effective in the later phase. The study thus documents that Citrus peels are good sources of anti-inflammatory and anti-nociceptive agents.
\end{abstract}

Key words: Citrus peel, Phytochemicals, Carrageenan, HRBC, Tail immersion, Hot Plate.

\section{INTRODUCTION}

Inflammation is a local response of living mammalian tissues to injury. It is a body defense reaction in order to eliminate or limit the spread of injurious agents typically characterized by an increase in tissue permeability and endothelial leukocyte influx of blood into the interstitium, causing edema. ${ }^{1-2}$ Though inflammation is a normal response to tissue injury, often it is uncontrolled in chronic autoimmune diseases such as rheumatoid arthritis and Crohn's disease, or when related to allergic response such as asthma and anaphylactic shock. ${ }^{2}$ Analgesia is an "unpleasant sensory and emotional experience that is caused by actual or potential tissue damage", usually evoked by an external and internal noxious stimulus. ${ }^{3-4}$ Inflammation and pain are common non-specific manifestations of many diseases. Various endogenous mediators such as histamine, serotonin, bradykinin, prostaglandins, etc are most abundant in inflammatory cells and among them prostaglandins are ubiquitous substances that indicate and modulate cell and tissue responses involved in pain and inflammation. ${ }^{5-6}$

The inflammatory agents exhibit therapeutic properties by blocking the action or synthesis of these mediators.
The most widely used medicines in modern practice are cyclooxygenase (COX) inhibitors i.e. NSAIDs and opioids which are effective for the treatment of inflammation and pain. ${ }^{7-8}$ These drugs block COX-1 and COX-2 enzymes involved in prostaglandin production. However, their chronic use particularly in patients with arthritis or other chronic inflammatory diseases is associated with adverse effects such as gastrointestinal perforation, ulceration, bleeding and renal toxicity mainly due to the blockade of COX-1. Therefore the need arises for the development of newer anti-inflammatory and analgesic agents from natural sources with more powerful activity and with lesser side effects as substitutes for chemical therapeutics. $^{7-10}$ In this context the present study was executed to explore for more naturally available alternatives, so that their therapeutic values can be assessed and expanded.

Several epidemiological studies have suggested that the consumption of fruit and vegetables is associated with a reduced risk of cardiovascular disorders and cancers, ${ }^{10-11}$ and neurodegenerative diseases such as Parkinson's and Alzheimer's diseases, ${ }^{12}$ as well as 
positive effects on inflammation and aging. ${ }^{13}$ The genus Citrus, which belong to the family of Rutaceae, is a rich bounty of edible fruits of different species and they are one of the main fruit tree crops grown throughout the world and have long been valued as part of a nutritious and tasty diet. The contribution of Citrus species in deterrence of life threatening diseases have been assessed and it has been reported that citrus fruits exhibit a wide range of promising biological properties due to their phenolic profile and antioxidant properties. In addition to this, it provides an ample supply of vitamins, minerals, dietary fibers, essential oils and carotenoids content which makes citrus a health-benefit promoting fruit. ${ }^{14-17}$ Although Citrus fruits are one of the most popular world fruit crops that are highly consumed worldwide as fresh produce, juice, most often the peel is discarded as waste which contains a wide variety of secondary components with substantial antioxidant activity in comparison with other parts of the fruit. ${ }^{17-18}$

Several studies have shown that citrus fruits exhibit pharmacological properties such as anti-cancer, ${ }^{19}$ antioxidant, anti-diabetic ${ }^{20}$ antipyritique, antitoxic, ${ }^{21}$ hypolipidemic, ${ }^{22}$ regulation of metabolic syndrome, ${ }^{23}$ delayed onset of Alzheimer's disease ${ }^{24}$ and many more. Recent literature also reviewed anti-inflammatory and analgesic activity in various citrus fruits. ${ }^{25}$ However the comparative study on peel of Citrus fruits localized to South India has not been evaluated. Therefore the present study aims to evaluate the pharmacological potential of ethanolic peel extracts of some selected commercially grown Citrus fruits of South India against pain and inflammation by both in vivo and in vitro methods in view of their use in the local treatment of some painful inflammatory conditions.

\section{MATERIALS AND METHODS}

\section{Collection of Plant material}

The Citrus fruits were procured from a local market of Shimoga, Karnataka. Which were authenticated by the Taxonomist, Department of Botany, Sahyadri Science College, Shimoga. The fruits selected include Lime (Citrus aurantifolia), Orange (Citrus reticulata), Sour Orange (Citrus aurantium), Pomello (Citrus grandis) and Citron (Citrus medica).

\section{Preparation of extracts}

The fruits selected were washed under running tap water followed by washing with distilled water to remove the surface debris. Then the peel of the fruits was separated and exactly $1000 \mathrm{~g}$ of the separated peel was subjected to extraction procedure using $70 \%$ ethanol. ${ }^{17}$

\section{Qualitative phytochemical analysis}

The phytochemical screening was performed for testing the different chemical groups present in peel extracts of all Citrus fruits. ${ }^{26-27}$

\section{Experimental animals}

Healthy adult Wistar strain of albino rats of both sexes, weighing 150-200 g were used for the in vivo evaluation. Animals were maintained under standard condition of 12:12 hours light/ dark cycle and at an ambient temperature of $23 \pm 2^{\circ} \mathrm{C}$, with $65 \pm 5 \%$ humidity. Animals were fed with standard rat chow pellet obtained from Champaka Foods and Feeds, Bangalore, India and water ad libitum. All the studies were conducted according to the ethical guidelines of CPCSEA after obtaining necessary clearance from the committee (NCP/IAEC/CL/244/2013-14 dated 24-03-2014).

\section{Acute Toxicity Studies}

Acute toxicity study was performed to ascertain any lethal effects of the extracts as per stair case method ${ }^{28}$ and mice were closely observed during the first $4 \mathrm{~h}$ after the administration of the treatments, and then once daily during the following 14 days. Even though, the animals were safe for maximum dose (5000-mg/kg-body weight) there were few changes in the behavioural response like alertness, touch response and restlessness. Therefore $1 / 20^{\text {th }}$ and $1 / 10^{\text {th }}$ of maximum tolerated dose i.e. 250 and 500 $\mathrm{mg} / \mathrm{kg}$ body weight were chosen for the study.

\section{Anti-inflammatory activity}

Carrageenan-induced paw oedema

The method used was similar to that described by Winter et al. ${ }^{29}$ The albino rats of either sex were divided into twelve groups of six animals each. Group I served as control and received the suspension of $0.1 \%$ carrageenan in physiological saline and Group II received Indomethacin at $20 \mathrm{mg} / \mathrm{Kg}$ body weight intraperitoneally as a standard drug. Group IIIXII received ethanolic extracts of Lime, Orange, Sour Orange, Pomello and Citron respectively at doses of 250 and $500 \mathrm{mg} / \mathrm{Kg}$ body weight. Acute edema in left hind paw of the rats was induced by the sub plantar injection of $0.1 \mathrm{ml}$ of freshly prepared $(1 \% \mathrm{w} / \mathrm{v})$ carrageenan suspension in normal saline $30 \mathrm{~min}$ after the drug administration. The paw volume was measured at $0,60,120,180,240$ and 300 min after the carrageenan injection using plethysmometer. Mean decrease in the paw volume was measured. The percentage inhibition of paw oedema was calculated by,

$$
\text { Percentage inhibition of paw oedema }=(1-\mathrm{Vt} / \mathrm{Vc}) \times 100
$$

Where,

$\mathrm{Vc}=$ increase in paw volume (average inflammation) of the control group of rats at a given time; and

$\mathrm{Vt}=$ inflammation of the peel extracts treated rats at the same time.

\section{Human erythrocyte membrane stabilization assay}

The HRBC membrane stabilization method was used to estimate in vitro anti-inflammatory activity of Citrus peel extracts. ${ }^{30}$ Blood was collected from healthy volunteers and was mixed with equal volume of sterilized Alsever's solution. This blood solution was centrifuged at $3000 \mathrm{rpm}$ and the packed cells were collected. The packed cells were washed with isosaline solution thrice and a $10 \% \mathrm{v} / \mathrm{v}$ suspension was made with isosaline. This HRBC suspension was used for the estimation of anti-inflammatory property. Different concentrations of extract and standard were separately mixed with $1 \mathrm{ml}$ of phosphate buffer, $2 \mathrm{ml}$ of hyposaline and 0.5 $\mathrm{ml}$ of $\mathrm{HRBC}$ suspension. All the assay mixtures were incubated at $37^{\circ} \mathrm{C}$ for $30 \mathrm{~min}$ and centrifuged at $3000 \mathrm{rpm}$ for $20 \mathrm{~min}$. The hemoglobin content in supernatant solution was estimated by a spectrophotometer at $560 \mathrm{~nm}$.

The hemolysis percentage was calculated by assuming the hemolysis produced by the control group as $100 \%$. The percentage of HRBC membrane stabilization or protection was calculated using the formula,

$$
\text { Percent protection }=100-(\mathrm{OD} \text { of extract treated sample } /
$$

$$
\text { OD of control) } \times 100 \text {. }
$$

\section{Antinociceptive activity}

Tail immersion test

The analgesic activity was determined by measuring drug-induced changes in the sensitivity of the mice to heat stress applied to their tails. ${ }^{31}$ Swiss albino mice weighing between 20-35 g were used for evaluation of analgesic activity. The selected mice were then divided in to twelve groups of six mice each. Group I served as control and received vehicle only intraperitoneally. Group II received diclofenac at a dose of $20 \mathrm{mg} / \mathrm{Kg}$ which served as standard. Group III-XII intraperitoneally received doses of 250 and $500 \mathrm{mg} / \mathrm{Kg}$ ethanolic extracts of Lime, Orange, Sour Orange, Pomello and Citron respectively. The initial reading was taken immediately before administration of drugs and then at 30,60, 90, 120,150, and 180 min after the administration. Tail flick latency difference or mean increase in latency after drug administration was used to indicate the analgesia produced by test and standard drugs. 


\section{Hot Plate method}

The paws of mice and rats are very sensitive to heat at temperatures which are not damaging the skin. ${ }^{32}$ The responses are jumping, withdrawal of the paws and licking of the paws. The animals are placed on the hot plate and the time until either licking or jumping occurs is recorded by a stopwatch. Swiss albino mice weighing between $20-35 \mathrm{~g}$ were used for evaluation of analgesic activity. Animals were divided into twelve groups, each group containing six animals each. Group I served as the control with no protection. Group II animals received the standard drug of Diclofenac $20 \mathrm{mg} / \mathrm{kg}$ body weight, whereas group III to XII animals were administered intraperitoneally with of ethanolic extracts Lime, Orange, Sour Orange, Pomello and Citron at a concentration of $250 \mathrm{mg}$ and $500 \mathrm{mg} / \mathrm{Kg}$ body weight respectively. The temperature of the hot plate was maintained $55 \pm 1^{\circ} \mathrm{C}$, mice were placed on the hot plate and the time in seconds (latency period) taken for mouse to react to the thermal pain by licking its paw or jumping was recorded. Observations were made before and after administration of respective drugs at an interval of $30 \mathrm{~min}$ for three hours.

\section{Statistical Analysis}

Data analyzed using one way analysis of variance (ANOVA) followed by Turkey's pair wise comparison test. Values are expressed as mean \pm SEM ( $n=6$ in each group). The results obtained were compared with the control group. P value $<0.01$ was considered statistically significant.

\section{RESULTS}

\section{Qualitative phytochemical analysis}

The preliminary qualitative phytochemical investigation documented that the peel extracts of all five citrus fruits showed the presence of many bioactive compounds viz. polyphenols, flavonoids, terpenoids, steroids, glycosides, alkaloids and carotenoids. However saponins were present in peel extracts of Orange, Citron and Sour Orange while absent in peel extracts of Lime and Pomello.

\section{Anti-inflammatory activity \\ Carrageenan-induced paw edema}

The effects of citrus peel extracts and standard indomethacin on paw edema induced by carrageenan are summarized in Table 1. Administration of carrageenan to the rats showed a steady rise in paw volume at different time intervals in control group and the standard drug Indomethacin treated group showed a constant decrease in paw edema volume. However administration of citrus peel extracts at different doses exhibited reduction in inflammation in a dose dependent manner. From the results it was evident that at $250 \mathrm{mg}$ the Lime, Orange, Sour Orange and Citron peel extracts exhibited significant $(P<0.01)$ reduction in paw edema at $3^{\text {rd }}$, $4^{\text {th }}$ and $5^{\text {th }}$ hour which was found to be $1.98 \pm 0.02,1.94 \pm 0.11,1.95 \pm 0.04$; $1.8 \pm 0.03,1.27 \pm 0.06,1.19 \pm 0.04 ; 1.94 \pm 0.04,1.86 \pm 0.08,1.83 \pm 0.05$ and $1.76 \pm 0.06,1.18 \pm 0.02,1.10 \pm 0.02$ manifesting a percent reduction of $10.15,25.45,17.56 ; 18.26,45.54,54.48 ; 12.17,20.61,30.14$ and 20.17, 49.62, 58.08 respectively. While Pomello peel extract showed significant reduction only at $5^{\text {th }}$ hour. The reduction in paw volume in Lime, Sour Orange and Pomello peels was prominent at $500 \mathrm{mg}$ dose recording mean values and percent inhibition of $[1.5 \pm 0.04(31.9 \%), 1.02 \pm 0.04$ (56.2\%), $1.19 \pm 0.04(54.7 \%)],[1.4 \pm 0.05$ (36.62\%), $0.96 \pm 0.06$ (58.66\%), $1.06 \pm 0.03(59.62 \%)]$ and $[1.74 \pm 0.05(21.32 \%), 1.34 \pm 0.07$ (42.46\%), $1.36 \pm 0.12(48.37 \%)]$ respectively at $3^{\text {rd }}, 4^{\text {th }}$ and $5^{\text {th }} \mathrm{h}$ respectively. But Citron and Orange peel extract elicited significant $(P<0.01)$ reduction of $1.52 \pm 0.04(10.87 \%), 1.61 \pm 0.08$ (23.71), $1.23 \pm 0.06$ (44.12), $0.71 \pm 0.03$ (69.32), $0.45 \pm 0.03(82.77)$ and $1.54 \pm 0.03(9.84 \%), 1.67 \pm 0.09(20.78 \%)$, $1.3 \pm 0.07$ (40.88\%), $0.86 \pm 0.04$ (63.29\%), $0.59 \pm 0.04(77.47 \%)$ at different time intervals. It is also evident from the data that the anti-inflammatory activity was positively correlated to time intervals exhibiting highest inhibition of paw volume at $3^{\text {rd }}$ and $4^{\text {th }}$ hour at all the treatment under study.

\section{Human erythrocyte membrane stabilization assay}

The protection of human blood erythrocyte membrane by five different peel extracts and the standard against lysis evoked by hypotonic solution was presented in the Table 2. From the results it was found that all the citrus peel extracts exhibited notable protection of the human RBC against the damaging effect of hypotonic solution in a dose dependent manner which was found to be highest at $25 \mathrm{mg} / \mathrm{ml}$ concentration where in the Citron peel extract showed maximum protection of $85.26 \pm 0.37 \%$ followed by Orange $(80.32 \pm 0.81)$, Sour Orange (54.43 \pm 0.9$)$, Lime (53.08 \pm 0.4$)$ and Pomello (45.77 \pm 0.87$)$. The standard indomethacin showed a maximum protection of $92.48 \pm 0.83 \%$ at $10 \mathrm{mg} / \mathrm{ml}$ concentration.

\section{Antinociceptive activity}

Analgesic effects of ethanolic extracts of five citrus peels by tail immersion and hot plate methods are presented in Table 3 and Table 4 respectively. The onset of reaction to thermal induced pain in both the models was significantly shorter in the control group than in those administered with extract or Diclofenac for any period of evaluation of pain. In tail immersion method a significant $(P<0.01)$ rise in reaction time was noticed at both $250 \mathrm{mg}$ and $500 \mathrm{mg}$ concentration by all the peel extracts at 120 and $150 \mathrm{~min}$ which were found to be $7.83 \pm 0.6,10.17 \pm 0.6 ; 9.83 \pm 0.6$, $12.67 \pm 0.84 ; \quad 8.33 \pm 0.49, \quad 10 \pm 0.68 ; \quad 6.83 \pm 0.6, \quad 8.83 \pm 0.65 ; \quad 10.17 \pm 0.79$, $13.5 \pm 0.85$ and $10.33 \pm 0.49,12.33 \pm 0.95 ; 12.83 \pm 0.83,15.67 \pm 1.05$; $10.83 \pm 0.7,13.17 \pm 0.79 ; 7.83 \pm 0.7,10.17 \pm 0.48 ; 13.17 \pm 0.7,17.33 \pm 0.88$ respectively for Lime, Orange, Sour Orange, Pomello and Citron. On the other hand in Hot plate method also a significant $(\mathrm{P}<0.01)$ elevation in reaction time was recorded at 120 and 150 min for both the concentrations of the extracts with latency time of $10.17 \pm 0.75,11.17 \pm 0.95$; $11.17 \pm 0.6, \quad 13.33 \pm 0.67 ; \quad 10.33 \pm 0.49, \quad 11.5 \pm 1.18 ; \quad 8.17 \pm 0.7, \quad 9.83 \pm 0.6$; $12.83 \pm 0.6,15.5 \pm 0.89$ and $11.33 \pm 0.56,13.17 \pm 0.79 ; 14.83 \pm 1.05,17.17 \pm 0.6$; $11.5 \pm 0.43,14.17 \pm 0.48 ; 9.5 \pm 0.56,11.5 \pm 0.76 ; 15.67 \pm 0.71,18.83 \pm 0.7$ at 250 and $500 \mathrm{mg}$ for Lime, Orange, Sour Orange, Pomello and Citron respectively. Standard drug Diclofenac recorded the reaction time of $5.17 \pm 0.75$, $6.83 \pm 0.48,10.5 \pm 0.62,14.67 \pm 1.2,18.17 \pm 1.11,15.67 \pm 0.71$ and $9.17 \pm 0.79$, $12.83 \pm 0.6,15.17 \pm 0.79,17.33 \pm 0.8,21.17 \pm 0.6,19.67 \pm 0.49$ in tail immersion and hot plate methods at different time intervals. Hence from the results, it was evident that the extracts showed dose dependent increase at different interval of time and the prominent increase was noted at 120 and $150 \mathrm{~min}$. It is also apparent from the data that, among the extracts the Citron peel extract was found to be highly effective for analgesic activity versus the other peel extracts irrespective of time intervals and dosage.

\section{DISCUSSION}

Recently, interests in potent pharmacological properties and clinical applications of natural products for replacing synthetic drugs are mounting. ${ }^{33}$ In spite of major scientific and technological progress in combinatorial chemistry, drugs derived from natural products still make an enormous contribution to drug discovery today. ${ }^{34}$ In this milieu, use of animal models in drug discovery and inflammation research is mainstay. As the inflammatory basis of disease becomes clear, anti-inflammatory food and food products become of greater interest. ${ }^{33-34}$ The research opportunities in nutrition to explore the relationship between a food and food components for an improved state of health and well-being or reduction of disease present the greatest challenge to scientists now and in the future. ${ }^{35} \mathrm{~A}$ lot of researches have documented that extracts from medicinal plants, fruits and vegetables contain such type of phytoconstit- 
Table 1: Anti-inflammatory effects of ethanolic extracts of five Citrus fruit peels on carrageenan induced paw edema.

\begin{tabular}{|c|c|c|c|c|c|c|}
\hline Treatment group & Dose & $60 \mathrm{~min}$ & $120 \mathrm{~min}$ & $180 \mathrm{~min}$ & $240 \mathrm{~min}$ & $300 \mathrm{~min}$ \\
\hline Control & & $1.7 \pm 0.03$ & $2.11 \pm 0.08$ & $2.2 \pm 0.03$ & $2.34 \pm 0.07$ & $2.63 \pm 0.04$ \\
\hline \multirow{3}{*}{ Standard } & $20 \mathrm{mg}$ & $1.26 \pm 0.02^{* *}$ & $1.3 \pm 0.02^{* *}$ & $0.95 \pm 0.04^{* *}$ & $0.62 \pm 0.06^{* *}$ & $0.3 \pm 0.03^{* *}$ \\
\hline & $\%$ & $25.65 \pm 1.94$ & $38.12 \pm 2.05$ & $56.8 \pm 2.12$ & $73.84 \pm 1.95$ & $88.62 \pm 1.16$ \\
\hline & $250 \mathrm{mg}$ & $1.65 \pm 0.05$ & $1.99 \pm 0.08$ & $1.98 \pm 0.02^{* *}$ & $1.94 \pm 0.11^{* *}$ & $1.95 \pm 0.04^{* *}$ \\
\hline \multirow{2}{*}{ Lime } & $\%$ & $3.09 \pm 1.11$ & $5.57 \pm 0.52$ & $10.15 \pm 0.81$ & $17.56 \pm 2.45$ & $25.45 \pm 1.78$ \\
\hline & $500 \mathrm{mg}$ & $1.58 \pm 0.04$ & $1.73 \pm 0.05^{* *}$ & $1.5 \pm 0.04^{* *}$ & $1.02 \pm 0.04^{* *}$ & $1.19 \pm 0.04^{* *}$ \\
\hline \multirow{6}{*}{ Orange } & $\%$ & $7.19 \pm 0.88$ & $17.64 \pm 2.09$ & $31.9 \pm 2.35$ & $56.2 \pm 2.13$ & $54.7 \pm 1.57$ \\
\hline & $250 \mathrm{mg}$ & $1.64 \pm 0.03$ & $1.96 \pm 0.08$ & $1.8 \pm 0.03^{* *}$ & $1.27 \pm 0.06^{\star *}$ & $1.19 \pm 0.04^{* *}$ \\
\hline & $\%$ & $3.52 \pm 0.41$ & $7.23 \pm 0.92$ & $18.26 \pm 1.04$ & $45.54 \pm 2.37$ & $54.48 \pm 2.16$ \\
\hline & $500 \mathrm{mg}$ & $1.54 \pm 0.03^{* *}$ & $1.67 \pm 0.09^{* *}$ & $1.3 \pm 0.07^{\star *}$ & $0.86 \pm 0.04^{* *}$ & $0.59 \pm 0.04^{* *}$ \\
\hline & $\%$ & $9.84 \pm 0.88$ & $20.78 \pm 1.89$ & $40.88 \pm 2.57$ & $63.29 \pm 1.71$ & $77.47 \pm 1.1$ \\
\hline & $250 \mathrm{mg}$ & $1.64 \pm 0.05$ & $1.97 \pm 0.08$ & $1.94 \pm 0.04^{\star *}$ & $1.86 \pm 0.08^{* *}$ & $1.83 \pm 0.05^{* *}$ \\
\hline \multirow{2}{*}{ Sour Orange } & $\%$ & $3.71 \pm 1.74$ & $6.67 \pm 0.57$ & $12.17 \pm 1.54$ & $20.61 \pm 2.19$ & $30.14 \pm 2.02$ \\
\hline & $500 \mathrm{mg}$ & $1.56 \pm 0.04^{\star}$ & $1.72 \pm 0.06^{\star *}$ & $1.4 \pm 0.05^{\star \star}$ & $0.96 \pm 0.06^{\star *}$ & $1.06 \pm 0.03^{* *}$ \\
\hline \multirow{6}{*}{ Pomello } & $\%$ & $8.82 \pm 1.09$ & $18.13 \pm 2.3$ & $36.62 \pm 2.58$ & $58.66 \pm 3.05$ & $59.62 \pm 1.38$ \\
\hline & $250 \mathrm{mg}$ & $1.66 \pm 0.06$ & $2.01 \pm 0.08$ & $2.07 \pm 0.04^{\star}$ & $2.08 \pm 0.04^{*}$ & $2.17 \pm 0.05^{\star *}$ \\
\hline & $\%$ & $2.76 \pm 1.73$ & $4.46 \pm 0.36$ & $6.16 \pm 0.91$ & $10.95 \pm 1.48$ & $17.28 \pm 1.46$ \\
\hline & $500 \mathrm{mg}$ & $1.61 \pm 0.05$ & $1.87 \pm 0.04^{*}$ & $1.74 \pm 0.05^{\star *}$ & $1.34 \pm 0.07^{* *}$ & $1.36 \pm 0.12^{* *}$ \\
\hline & $\%$ & $5.88 \pm 1.16$ & $10.9 \pm 2.32$ & $21.32 \pm 1.69$ & $42.46 \pm 3.51$ & $48.37 \pm 3.79$ \\
\hline & $250 \mathrm{mg}$ & $1.64 \pm 0.03$ & $1.94 \pm 0.07$ & $1.76 \pm 0.06^{* *}$ & $1.18 \pm 0.02^{\star *}$ & $1.10 \pm 0.02^{* *}$ \\
\hline \multirow{3}{*}{ Citron } & $\%$ & $4.01 \pm 0.39$ & $7.87 \pm 0.49$ & $20.17 \pm 2.01$ & $49.62 \pm 1.78$ & $58.08 \pm 1.45$ \\
\hline & $500 \mathrm{mg}$ & $1.52 \pm 0.04^{* *}$ & $1.61 \pm 0.08^{* *}$ & $1.23 \pm 0.06^{* *}$ & $0.71 \pm 0.03^{* *}$ & $0.45 \pm 0.03^{* *}$ \\
\hline & $\%$ & $10.87 \pm 1.22$ & $23.71 \pm 2.37$ & $44.12 \pm 2.86$ & $69.32 \pm 1.91$ & $82.77 \pm 0.88$ \\
\hline
\end{tabular}

P values: ${ }^{* *} \mathrm{P}<0.01,{ }^{*} \mathrm{P}<0.05$, Values are expressed in mean $\pm \mathrm{SEM}, \mathrm{n}=6$ animals in each group. One way ANOVA followed by Turkey’s, Pairwise comparison tests

Table 2: Anti -inflammatory effects of ethanolic extracts of five Citrus fruit peels and standard indomethacin on HRBC membrane stabilization assay.

\begin{tabular}{|c|c|c|c|c|c|c|c|}
\hline $\begin{array}{l}\text { Concentration } \\
(\mathrm{mg} / \mathrm{ml})\end{array}$ & Lime & Orange & Sour Orange & Pomello & Citron & $\begin{array}{c}\text { Concentration } \\
(\mathrm{mg} / \mathrm{ml})\end{array}$ & Standard \\
\hline 5 & $11.86 \pm 0.41$ & $17.4 \pm 0.56$ & $17.33 \pm 0.46$ & $2.42 \pm 0.42$ & $22.22 \pm 0.32$ & 2 & $17.65 \pm 0.85$ \\
\hline 10 & $23.39 \pm 0.29$ & $34.97 \pm 0.56$ & $31.11 \pm 0.56$ & $12.56 \pm 0.84$ & $39.16 \pm 0.37$ & 4 & $37.4 \pm 0.53$ \\
\hline 15 & $34.55 \pm 0.41$ & $55.3 \pm 0.96$ & $40.22 \pm 0.49$ & $19.44 \pm 0.7$ & $55.34 \pm 0.37$ & 6 & $59.7 \pm 1.09$ \\
\hline 20 & $45.7 \pm 0.2$ & $67.78 \pm 1.04$ & $51.25 \pm 0.68$ & $30.43 \pm 0.89$ & $76.18 \pm 0.32$ & 8 & $76.38 \pm 0.96$ \\
\hline 25 & $53.08 \pm 0.4$ & $80.32 \pm 0.81$ & $54.43 \pm 0.91$ & $45.77 \pm 0.87$ & $85.26 \pm 0.37$ & 10 & $92.48 \pm 0.83$ \\
\hline
\end{tabular}

Table 3: Effect of ethanolic extracts of five Citrus fruit peels in tail immersion model of analgesia in mice.

\begin{tabular}{|c|c|c|c|c|c|c|c|c|}
\hline Treatment Group & $\begin{array}{l}\text { Dose } \\
(\mathrm{mg})\end{array}$ & $0 \mathrm{~min}$ & $30 \mathrm{~min}$ & $60 \mathrm{~min}$ & $90 \mathrm{~min}$ & $120 \mathrm{~min}$ & $150 \mathrm{~min}$ & $180 \mathrm{~min}$ \\
\hline Control & & $2.67 \pm 0.21$ & $2.67 \pm 0.33$ & $2.5 \pm 0.22$ & $2.67 \pm 0.33$ & $2.67 \pm 0.33$ & $2.5 \pm 0.22$ & $2 \pm 0.26$ \\
\hline Standard & 20 & $2.83 \pm 0.17$ & $5.17 \pm 0.75 *$ & $6.83 \pm 0.48^{* *}$ & $10.5 \pm 0.62^{* *}$ & $14.67 \pm 1.2^{* *}$ & $18.17 \pm 1.11^{* *}$ & $15.67 \pm 0.71^{* *}$ \\
\hline \multirow{2}{*}{ Lime } & 500 & \multirow{2}{*}{$2.67 \pm 0.33$} & $4.0 \pm 0.37^{*}$ & $5.33 \pm 0.42^{* *}$ & $7.83 \pm 0.79^{* *}$ & $10.17 \pm 0.6^{* *}$ & $12.33 \pm 0.95^{* *}$ & $11.5 \pm 0.85^{\star *}$ \\
\hline & 250 & & $2.83 \pm 0.4$ & $3.33 \pm 0.33^{*}$ & $5.67 \pm 0.42^{* *}$ & $7.83 \pm 0.6^{* *}$ & $10.33 \pm 0.49^{* *}$ & $8.83 \pm 0.48^{* *}$ \\
\hline \multirow{2}{*}{ Orange } & 500 & \multirow{2}{*}{$2.83 \pm 0.4$} & $4.67 \pm 0.61^{*}$ & $6.00 \pm 0.37^{* *}$ & $9.67 \pm 1.05^{* *}$ & $12.67 \pm 0.84^{* *}$ & $15.67 \pm 1.05^{* *}$ & $13.67 \pm 0.76^{* *}$ \\
\hline & 250 & & $3 \pm 0.52$ & $4.00 \pm 0.52^{*}$ & $7.17 \pm 0.6^{* *}$ & $9.83 \pm 0.6^{* *}$ & $12.83 \pm 0.83 * *$ & $10.67 \pm 0.71^{\star *}$ \\
\hline \multirow{2}{*}{ Sour Orange } & 500 & \multirow{2}{*}{$2.67 \pm 0.33$} & $4.17 \pm 0.31^{*}$ & $5.33 \pm 0.42^{* \star}$ & $8.0 \pm 1.18^{\star *}$ & $10 \pm 0.68^{* *}$ & $13.17 \pm 0.79^{\star *}$ & $11.17 \pm 0.54^{* *}$ \\
\hline & 250 & & $2.83 \pm 0.31$ & $3.17 \pm 0.31$ & $6.17 \pm 0.48^{\star *}$ & $8.33 \pm 0.49^{* *}$ & $10.83 \pm 0.7^{\star *}$ & $9.17 \pm 0.6^{* *}$ \\
\hline \multirow{2}{*}{ Pomello } & 500 & \multirow{2}{*}{$2.67 \pm 0.33$} & $3.17 \pm 0.31$ & $4.0 \pm 0.52$ ** & $6.67 \pm 0.76^{* *}$ & $8.83 \pm 0.65^{* *}$ & $10.17 \pm 0.48^{\star *}$ & $9.17 \pm 0.48^{\star *}$ \\
\hline & 250 & & $2.67 \pm 0.33$ & $2.83 \pm 0.31$ & $4.17 \pm 0.48^{*}$ & $6.83 \pm 0.6^{* *}$ & $7.83 \pm 0.7^{* *}$ & $7.00 \pm 0.45^{\star *}$ \\
\hline \multirow{2}{*}{ Citron } & 500 & \multirow{2}{*}{$2.67 \pm 0.21$} & $4.83 \pm 0.87^{*}$ & $6.67 \pm 0.33^{* *}$ & $9.83 \pm 0.6^{* *}$ & $13.5 \pm 0.85^{\star *}$ & $17.33 \pm 0.88^{* *}$ & $14.83 \pm 1.05^{* *}$ \\
\hline & 250 & & $3.17 \pm 0.31$ & $4.17 \pm 0.48^{*}$ & $8.5 \pm 1.12 * *$ & $10.17 \pm 0.8^{* *}$ & $13.17 \pm 0.7^{* *}$ & $11.83 \pm 0.79^{* *}$ \\
\hline
\end{tabular}

P values: ${ }^{*} \mathrm{P}<0.01$ Values are expressed in mean \pm SEM, $\mathrm{n}=6$ animals in each group. One way ANOVA followed by Turkey's, Pairwise comparison tests 
Malleshappa, et al.: Antiinflammatory and Analgesic Potentials of Citrus fruits peel

Table 4: Effect of ethanolic extracts of five Citrus fruit peels in Hot plate model of analgesia in mice.

\begin{tabular}{|c|c|c|c|c|c|c|c|c|}
\hline Treatment Group & Dose(mg) & $0 \mathrm{~min}$ & $30 \mathrm{~min}$ & $60 \mathrm{~min}$ & $90 \mathrm{~min}$ & $120 \mathrm{~min}$ & $150 \mathrm{~min}$ & $180 \mathrm{~min}$ \\
\hline Control & & $5.33 \pm 0.61$ & $5.5 \pm 0.43$ & $5.67 \pm 0.42$ & $5.33 \pm 0.42$ & $5.5 \pm 0.43$ & $5.33 \pm 0.49$ & $4.33 \pm 0.33$ \\
\hline $\begin{array}{c}\text { Standard } \\
\text { Diclofenac Sodium }\end{array}$ & 20 & $5.67 \pm 0.67$ & $9.17 \pm 0.79^{* *}$ & $12.83 \pm 0.6^{* *}$ & $15.17 \pm 0.79^{* *}$ & $17.33 \pm 0.8^{* *}$ & $21.17 \pm 0.6^{* *}$ & $19.67 \pm 0.49^{* *}$ \\
\hline \multirow{2}{*}{ Lime } & 500 & \multirow{2}{*}{$5.00 \pm 0.37$} & $5.83 \pm 0.6$ & $8 \pm 0.58^{* *}$ & $10.5 \pm 0.76^{* *}$ & $11.17 \pm 0.95^{* *}$ & $13.17 \pm 0.79^{\star *}$ & $11.5 \pm 0.56^{* *}$ \\
\hline & 250 & & $5.17 \pm 0.31$ & $7.33 \pm 0.56^{*}$ & $9.17 \pm 0.48^{* *}$ & $10.17 \pm 0.75^{\star *}$ & $11.33 \pm 0.56^{\star *}$ & $10.17 \pm 0.7^{* *}$ \\
\hline \multirow{2}{*}{ Orange } & 500 & \multirow{2}{*}{$5.17 \pm 0.54$} & $7.33 \pm 0.49$ & $9.67 \pm 0.67^{\star *}$ & $11.17 \pm 0.6^{* *}$ & $13.33 \pm 0.67$ ** & $17.17 \pm 0.6^{\star *}$ & $15.33 \pm 0.88^{* *}$ \\
\hline & 250 & & $6.5 \pm 0.56$ & $8.83 \pm 0.54^{\star *}$ & $9.83 \pm 0.48^{* *}$ & $11.17 \pm 0.6^{\star *}$ & $14.83 \pm 1.05^{\star *}$ & $12.67 \pm 0.33^{\star *}$ \\
\hline \multirow{2}{*}{ Sour Orange } & 500 & \multirow{2}{*}{$5.5 \pm 0.34$} & $6.17 \pm 0.31$ & $8.33 \pm 0.71^{* *}$ & $10.83 \pm 0.91^{\star *}$ & $11.5 \pm 1.18^{* *}$ & $14.17 \pm 0.48^{* *}$ & $12.33 \pm 0.42^{* *}$ \\
\hline & 250 & & $5.33 \pm 0.42$ & $7.17 \pm 0.48^{*}$ & $9.17 \pm 0.48^{* *}$ & $10.33 \pm 0.49^{* *}$ & $11.5 \pm 0.43^{\star *}$ & $10.17 \pm 0.79^{* *}$ \\
\hline \multirow{2}{*}{ Pomello } & 500 & \multirow{2}{*}{$5.00 \pm 0.52$} & $5.33 \pm 0.42$ & $7.33 \pm 0.76$ & $8.17 \pm 0.48^{* *}$ & $9.83 \pm 0.6^{\star *}$ & $11.5 \pm 0.76^{\star *}$ & $9.67 \pm 0.67 * *$ \\
\hline & 250 & & $5.17 \pm 0.31$ & $6.17 \pm 0.6$ & $7.33 \pm 0.61 *$ & $8.17 \pm 0.7^{* *}$ & $9.5 \pm 0.56$ ** & $8.33 \pm 0.33 * *$ \\
\hline \multirow{2}{*}{ Citron } & 500 & \multirow{2}{*}{$5.17 \pm 0.48$} & $8.67 \pm 0.33^{\star *}$ & $10.83 \pm 0.4^{\star *}$ & $12.67 \pm 0.67^{* *}$ & $15.5 \pm 0.89^{\star *}$ & $18.83 \pm 0.7^{\star *}$ & $17 \pm 0.68^{* *}$ \\
\hline & 250 & & $7.5 \pm 0.5 *$ & $9.67 \pm 0.33^{* *}$ & $11.00 \pm 0.52^{* *}$ & $12.83 \pm 0.6^{\star *}$ & $15.67 \pm 0.71^{\star *}$ & $14 \pm 0.58^{* *}$ \\
\hline
\end{tabular}

P values: ${ }^{*} \mathrm{P}<0.01$ Values are expressed in mean \pm SEM, $\mathrm{n}=6$ animals in each group. One way ANOVA followed by Turkey’s, Pairwise comparison tests

uents that might be responsible for treating diseases. ${ }^{13,36}$ The peel of citrus fruits is reported to have several beneficial activities. ${ }^{37}$ In traditional Chinese medicine, the dried peel of Citrus reticulate has been widely used for centuries as a remedy for treating indigestion and fighting respiratory tract inflammatory syndromes such as asthma and bronchitis. ${ }^{38}$ In the present study, peels of five different citrus fruits namely Lime, Orange, Sour Orange, Pomello and Citron commonly grown in South India were used for the evaluation of anti-inflammatory and analgesic activities by using reliable in vivo and in vitro models to provide scientific support to rationalize the folklore or traditional claims for treating inflammation.

Carrageenan-induced inflammation is a sensitive and most feasible experimental model of acute inflammation for detecting active nonsteroidal anti-inflammatory agents. ${ }^{39}$ The development of carrageenaninduced edema is bi-phasic; the first phase is attributed to the release of histamine, serotonin and kinins and the second phase is associated to the release of prostaglandins and bradykinins. ${ }^{40-44}$ The suppression of the first phase may be due to inhibition of the release of early mediators, such as histamine and serotonin, and the action in the second phase may be explained by an inhibition of cyclo-oxygenase. It has been reported that second phase of oedema is sensitive to most clinically effective anti-inflammatory drugs, which has been frequently used to access the anti-oedematous effect of natural products. ${ }^{45-46}$ The results of the present research revealed that peels of all the citrus fruits studied possessed a significant anti-oedematogenic effect on paw oedema induced by carrageenan. From the results it was observed that Citron peel extract showed maximum reduction in paw volume at $3^{\text {rd }} 4^{\text {th }}$ and $5^{\text {th }}$ hour time interval in a dose dependent manner which is almost equal to standard drug indomethacin followed by peel extracts of Orange, Sour Orange, Lime and Pomello respectively. In general, the anti-inflammatory activity is more evident at the later phases of time interval. Therefore, it can be inferred that the inhibitory effect of different extracts on carrageenan-induced inflammation could be due to inhibition of the enzyme cyclooxygenase leading to inhibition of prostaglandin synthesis. ${ }^{47}$

Further HRBC method was selected for the in vitro evaluation of antiinflammatory property because the erythrocyte membrane is analogous to the lysosomal membrane $\mathrm{e}^{48}$ and its stabilization implies that the extract may as well stabilize lysosomal membranes. Stabilization of lysosomal membrane is important in limiting the inflammatory response by preventing the release of lysosomal constituents of activated neutrophil, such as bactericidal enzymes and proteases, which cause further tissue inflammation and damage upon extra cellular release. There is increasing evidence that lysosomal enzymes play an important role in the development of acute and chronic inflammation. ${ }^{49}$ Most of the anti-inflammatory drugs exert their beneficial effect by inhibiting either release of lysosomal enzymes or by stabilizing lysosomal membrane which is one of the major events responsible for the inflammatory process. ${ }^{50}$ Extracts of all the Citrus fruits showed significant stabilization towards hypotonicity induced HRBC membrane lysis at different concentrations in a dose dependent manner. However Citron peel revealed a higher percentage protection followed by Orange, Sour Orange, Lime and Pomello. These results provide evidence for membrane stabilization as an additional mechanism of their anti-inflammatory effect. Thus the stabilization of RBCs membrane further establishes the anti-inflammatory potentials of Citrus peel extracts.

Pain is a complex event, centrally modulated via a number of complex processes including opiate, dopaminergic, descending noradrenergic and serotonergic systems. ${ }^{47}$ In the present study thermal nociception hot plate and tail immersion tests have been used to assess the analgesic property of the extracts. The tests are very useful for discriminating between centrally acting morphine like analgesics and non-opiate analgesics, giving positive response to the former only. ${ }^{51-52}$ It was evident from the results that all the peel extracts possess potent analgesic property in a dose dependent manner however; Citron peel extract at $500 \mathrm{mg} / \mathrm{Kg}$ body weight was found to be more effective than the others irrespective of time intervals. The analgesic effect produced by the tests may be via central mechanisms involving mentioned receptor systems.

The preliminary qualitative phytochemical analysis documented that, all the extracts of citrus fruits are bestowed with the presence of therapeutically effective bioactive compounds viz. polyphenols, flavonoids, terpenoids, steroids, tannins, glycosides, alkaloids and carotenoids. The core chemical classes of anti-inflammatory and analgesic agents have been reported from natural sources containing polyphenols, flavonoids, alkaloids, terpenoids, saponins, steroids and tannins. ${ }^{53}$ These phytochemicals act by the inhibition of mediators which probably play a key role in preventing inflammation, as because inflammatory cytokines induces cyclooxygenase-2 (COX-2) and prostaglandin E2 synthesis, which have a critical role in the pathogenesis of inflammatory diseases. ${ }^{54}$ The phenolic compounds present in plants are found to possess potent anti-inflammatory activity which was reported by Roy et al..$^{55}$ Garg et al. ${ }^{56}$ Among the various, flavonoids have beneficial effects in a number of 
Malleshappa, et al.: Antiinflammatory and Analgesic Potentials of Citrus fruits peel

inflammatory conditions. Some of them act as phospholipase inhibitors and some have been reported as TNF- $\alpha$ inhibitors in different inflammatory situations. ${ }^{53}$ Flavonoids are known to inhibit the enzyme prostaglandin synthetase, more specifically the endoperoxidase and reported to produce anti-inflammatory effects. ${ }^{57}$ Since, prostaglandins are also involved in the pain perception inhibition of their synthesis and distraction of synthesis of eicosanoids by flavonoids might be the possible reason for the analgesic activity of the extract. ${ }^{58-59}$ Indeed, many essential oils showed inhibitory activity against the production of cytokines have shown that flavonoids and limonoid present in the plant Citrus are responsible for the anti - tumor and anti-inflammatory activity ${ }^{60}$ The possible activity of citrus flavonoids in anti-inflammatory and anti-allergic responses was well documented. ${ }^{61}$ Lee et al. reported that Citrus flavonoids are able to inhibit the kinases and phosphodiesterases essential for cellular signal transduction and activation and inhibit cells involved in inflammation and the immune response. ${ }^{62}$ There are also reports on the role of tannins in anti-nociceptive activity. ${ }^{63}$ Apart from this, phytosterols have been reported to lower some of the pro-inflammatory cytokines including C-reactive protein ${ }^{64}$ and alkaloids have been found to have pain-killing activity ${ }^{65}$ suggesting their role against inflammation. The anti-inflammatory effects of triterpenes have been attributed to various mechanisms including inhibition of lipoxygenase and cycloxygenase activities. ${ }^{66}$ Hence the analgesic and anti-inflammatory effects produced by the citrus peel extracts may be attributed individually or collectively to the flavonoids, limonoids, steroids, alkaloids, terpenes and tannins. Of all the mechanisms for the anti-inflammatory effects of the plants, their actions on endogenous pro-inflammatory mediators are remarkable.

From the above verdicts it can be concluded that the ethanolic extract of all citrus peels possessed promising anti-inflammatory and analgesic activities. The study also revealed that the peel extracts of Citron possessed a significant anti-oedematogenic, anti-haemolytic and analgesic effect followed by Orange, Sour Orange, Lime and Pomello peel extracts. This significant action of the peel extracts may be due to the inhibition of any inflammatory mediators coupled with lysosomal membrane stability by the phytoconstituents present in the extracts.

\section{CONCLUSION}

Citrus fruits are considered as an exemplary source of nutrients and bioactive compounds. The results of present study authentify the folk lore information on the anti-inflammatory and analgesic property of citrus fruits. It can be concluded that the peels of all the citrus fruits studied possess potent anti-inflammatory and anti-nociceptive activity. The broad range of activity of the extracts suggests that, multiple mechanisms mediated by the phytoconstituents are responsible for the potent activity. Hence the study demonstrates the efficacy of peels of Lime, Orange, Sour Orange, Pomello and Citron as effective therapeutic agents in the treatment of acute inflammations. The research will be useful in optimization of composition of fruits and would be a very cost-effective approach of disease prevention, since diet-induced health improvements would not carry any added costs for the health sector and will be of immense help in functional food industry.

\section{CONFLICT OF INTEREST}

The authors declare no conflict of interest.

\section{ABBREVIATIONS}

HRBC: Human Red Blood Cell; NSAID's: Non Steroidal Antiinflammatory Drugs; COX: Cyclooxygenase; TNF-a: Tumor Necrosis Factor alpha.

\section{REFERENCES}

1. John NAA, Shobana G. Anti-inflammatory activity of Talinum fruticosum L. on formalin induced paw edema in albino rats. Journal of Applied Pharmaceutical Science. 2012;2(1):123-7.

2. Robbins S, Kumar V, Abbas AK. Pathological Basis of Disease. $7^{\text {th }}$ ed. Elsevier Saunders: Philadelphia. 2005.

3. Tripathi KD. Essentials of medical pharmacology. $5^{\text {th }}$ ed. Jaypee Brothers Medical Publishers: Delhi. 2003.

4. Gupta S, Singh A. Antimicrobial, Analgesic and Anti - Inflammatory Activity Reported on Tamarindus indica Linn Root Extract. Pharmacognosy Journal. 2017;9(3):410-6.

5. Maldini M, Sosa S, Montoro P, Giangaspero A, Balick MJ, Pizza C, et al. Screening of the topical anti-inflammatory activity of the bark of Acacia cornigera Willdenow, Byrsonima crassifolia Kunth, Sweetia panamensis Yakovlev and the leaves of Sphagneticola trilobata Hitchcock. Journal of Ethnopharmacology. 2009;122(3):430-3.

6. Hossain MS, Alam MB, Chowhdury NS, Asadujiaman M, Zahan R, Islam MM et al. Antioxidant, analgesic and anti-inflammatory activities of the herb Eclipta prostrata. Journal of Pharmacology and Toxicology. 2011;6:468-80.

7. Wahyuni FS, Ali DAl, Lajis NH, Dachriyanus. Anti-inflammatory activity of isolated compounds from the stem bark of Garcinia cowa Roxb. Pharmacognosy Journal. 2017;9(1):55-7.

8. Calixto JB, Cabrini DA, Ferreira J, Campos MM. Kinins in pain and inflammation. Pain. 2000;87:1-5

9. Rajalakshmi P, Vadivel V, Brindha P. Investigation of in vitro Antioxidant and Antiinflammatory Activities of Selected Siddha Polyherbal Formulations. Indian J of Pharmaceutical Education and Research. 2017;51(4S):S747-S753.

10. Ames BN. Dietary carcinogens and anticarcinogens: oxygen radicals and degenerative diseases. Science. 1983;221(4617):1256-64.

11. Kris-Etherton PM, Hecker KD, Bonanome A, Coval SM, Binkoski AE, Hilpert KF, et al. Bioactive compounds in foods: their role in the prevention of cardiovascular diseases and cancer. The American Journal of Medicine. 2002;113(9):71-88.

12. Matteo VD, Esposito E. Biochemical and therapeutic effects of antioxidants in the treatment of Alzheimer's disease, Parkinson's disease, and amyotrophic lateral sclerosis. Current Drug Targets - CNS and Neurological Disorders. 2003;2(2):95-107.

13. Ames BN, Shigenaga MK, Hagen TM. Oxidants, antioxidants, and the degenerative diseases of aging. Proc Natl Acad Sci USA. 1993;90(17):7915-22.

14. Gorinstein S, Cvikrova M, Machackova I, Haruenkit R, Park YS, Jung ST. Characterization of antioxidant compounds in Jaffa sweeties and white grapefruits. Food Chemistry. 2004;84(4):503-10.

15. Guimaraes R, Barros L, Barreira JCM, Sousa MJ, Carvalho AM, Ferreira IC Targeting excessive free radicals with peels and juices of citrus fruits: grapefruit, lemon, lime and orange. Food and Chemical Toxicology. 2009;48(1):99-106.

16. Codoner-franch $P$, Valls-belles V. Citrus as functional foods. Current Topics in Nutraceutical Research. 2010;8(4):173-84.

17. Pallavi M, Ramesh CK, Krishna V, Parveen S, Swamy NL. Quantitative phytochemical analysis and antioxidant activities of some Citrus fruits of South India. Asian Journal Pharmaceutical and Clinical Research. 2017;10:198-205.

18. Manthey JA, Grohmann K. Phenols in Citrus peel byproducts: Concentrations of hydroxycinnamates and polymethoxylated flavones in Citrus peel molasses. Journal of Agricultural and Food Chemistry. 2001;49(7):3268-73.

19. Kim H, Moon JY, Mosaddik A, Cho SK. Induction of apoptosis in human cervical carcinoma HeLa cells by polymethoxylated flavone-rich Citrus grandis Osbeck leaf extract. Food Chemistry and Toxicology. 2010;48(8-9):2435-42.

20. Kim GN, Shin JG, Jang HD. Antioxidant and antidiabetic activity of Dangyuja (Citrus grandis Osbeck) extract treated with Aspergillus saitoi. Food Chemistry. 2009;117(1):35-41.

21. Arias BA, Ramon-Laca L. Pharmacological properties of Citrus and their ancient and medieval uses in the Mediterranean region. Journal of Ethnopharmacology. 2005;97(1):89-95

22. Kou MC, Fu SH, Weng CY, Yen JH, Li S, HO CT, et al. Effects of Citrus flavonoids 5-hydroxy-3,5,6,7,8,3-,4-hexamethoxyflavone and 3,5,6,7,8,3-,4-heptamethoxyflavone, on the activities of macrophage scavenger receptors and the hepatic LDL receptor. Food and Function. 2013;4(4):602-9.

23. Gorinstein S, Caspi A, Libman I, Lerner HT, Huang D, Leontowicz H, et al. Red grapefruit positively influences serum triglyceride level in patients suffering from coronary atherosclerosis: studies in vitro and in humans. Journal of Agricultural and Food Chemistry. 2006;54(5):1887-92.

24. Nakajima A, Aoyama Y, Nguyen TT, Shin EJ, Kim HC, Yamada S, et al. Nobiletin, a Citrus flavonoid, ameliorates cognitive impairment, oxidative burden and hyper phosphorylation of tau in senescence-accelerated mouse. Behavioral Brain Research. 2013;250:351-60.

25. Chaudhari SY, Ruknuddin G, Prajapati P. Ethno medicinal values of Citrus genus: A review. Medical Journal of Dr. Dy Patil Vidyapeeth. 2016;9(5):560-5.

26. Trease GE, Evans WC. A Text Book of Pharmacognosy, $11^{\text {th }}$ ed. London: Bailliere Tidall. 1978;530 
27. Kokate CK, Purohith AP, Gokhale SB. Pharmacognosy, Pune: Nirali Prakashan. 1990;120

28. Ghosh MN. Fundamentals of Experimental Pharmacology, $2^{\text {nd }}$ ed. Scientific book agency: Calcutta 1984.

29. Winter CA, Risley EA, Nuss GW. Experimental Biology. 1962;111:544-7.

30. Tantary S, Masood A, Bhat AH, Dar KB, Zargar MA, Ganie SA. In vitro antioxidant and RBC membrane stabilization activity of Euphorbia wallichii. Free Radicals and Antioxidants. 2017;7(1):13-22

31. Kulkarni SK. Handbook of Experimental Pharmacology, $1^{\text {st }}$ ed. Delhi: vallabh prakashan. 1987;63-4

32. Suresha RN, Amoghimath S, Vaibhavi PS, Shruthi SL, Jayanthi MK, Kalabharathi $\mathrm{HL}$. Evaluation of analgesic activity of perindopril in albino mice. Journal of Advanced Pharmaceutical Technology and Research. 2014;5(3):129-33.

33. Herath KHINM, Bing SJ, Cho J, Kim A, Shin S, Kim GO, et al. Anti-inflammatory activities of Dangyuja (Citrus grandis Osbeck) in concanavalin A stimulated murine splenocytes and 12-O-tetradecanoylphorbol-13-acetate-induced murine skin edema. Biomedicine Pharmacotherapy. 2016;83:1353-64.

34. Yuan GF, Wahlqvist ML, He GQ, Yang M, Li D. Natural products and anti-inflammatory activity. Asia Pacific Journal of Clinical Nutrition. 2006;15(2):143-52.

35. Ramesh CK, Jamuna KS, Raghavendra. Concepts and trends of functional foods: A review. International Journal of Pharmaceutical Research and Development. 2012;4(6):273-90

36. Radhika G, Sudha V, Mohan SR, Ganesan A, Mohan V. Association of fruit and vegetable intake with cardiovascular risk factors in urban south Indians. British Journal of Nutrition. 2008;99(2):398-405

37. Murakami A, Nakamura Y, Torikai K, Tanaka T, Koshiba T, Koshimizu K, et al. Inhibitory effect of Citrus nobiletin on phorbol ester-induced skin inflammation, oxidative stress, and tumor promotion in mice. Cancer Research. 2000;60(18):5059-66.

38. Ho SC, Lin CC. Investigation of heat treating conditions for enhancing the antiinflammatory activity of Citrus fruit (Citrus reticulate) peels. Journal of Agricultural Food and Chemistry. 2008;56(17):7976-82

39. Sawadogo WR, Boly R, Lompo M, Some N, Lamien CE, Guissou IP, et al. Antiinflammatory, analgesic and antipyretic activities of Dicliptera verticillata. International Journal of Pharmacology. 2006;2:435-8.

40. Kapewangolo P, Omolo JJ, Bruwer R, Fonteh P, Meyer D. Antioxidant and antiinflammatory activity of Ocimum labiatum extract and isolated labdane diterpenoid. Journal of Inflammation. 2015;12(1):4.

41. Yeshwante SB, Juvekar AR, Nagmoti DM, Wankhede SS, Shah AS, Pimprikar RB, et al. Anti-infammatory activity of methanolic extracts of Dillenia indica L. Leaves. J Young Pharm. 2009;1:63-6.

42. Vinaykumar S, Rathnakar UP, Dinkar US, Priyanka K, Gaurav T, Kudgi AS, et al. Anti-inflammatory activity of BCM-95 (bio-enhanced formulation of turmeric with increased bioavailabilty) compared to Curcumin in Wistar rats. Pharmacognosy Journal. 2016;8(4):380-84

43. Singh $M$, Kumar $V$, Singh I, Gauttam $V$, Kalia NA. Anti-inflammatory activity of aqueous extract of Mirabilis jalapa Linn. Leaves. Pharmacognosy Research. 2010;2(6):364-7.

44. Vinegar R, Schreiber WR. Biphasic development of carrageenan edema in rats. Journal of Pharmacology and Experimental Therapeutics.1969;166(1):96-103.

45. Rosa MD. Biological properties of Carrageenan. J Pharm Pharmacol. 1972;24(2):89-102.

46. Loggia AD, Tubaro A, Dri P, Zilli C, Negro PD. The role of flavonoids in the antiinflammatory activity of Chamomilla recutita. Progress in Clinical and Biological Research. 1968;213:481-86.

47. Ekbote MT, Ramesh CK, Mahmood R, Thippeswamy BS, Veerapur V. Antiinflammatory and analgesic activities of Azima tetracantha Lam leaves. Journal of Pharmacy Research. 2010;3(3):478-81
48. Shenoy S, Shwetha K, Prabhu K, Maradi R, Bairy KL, Shanbhag T. Evaluation of anti-inflammatory activity of Tephrosia purpurea in rats. Asian Pacific Journal of Tropical Medicine. 2010;3(3):193-5.

49. Anderson AJ, Bocklehurst WE, Wills AL. Evidence for the role of lysosomes in the formation of prostaglandins during carrageenan induced inflammation in rat. Pharmacological Research communications. 1971;3(1):13-7.

50. Nair RB, Ravishankar B, Vijayan NP, Sasikala CK, Saraswathy VN. Anti inflammatory effect of Strbilanthus heyneanus Leaves-A biochemical study. Journal of Research in Ayurrveda and Siddha. 1988;9(1-2):46

51. Woolfe G, MacDonald AD. The evaluation of the analgesic action of pethidine hydrochloride (DEMEROL). Journal of Pharmacology and Experimental Therapeutics 1944;80(3):300-7.

52. Srinivasan K, Muruganandan S, Lal J, Chandra S, Tandan SK, Raviprakash V. Antinoniceptive and antipyretic activities of Pongamia pinnata leaves. Phytotherapy Research. 2003;17(3):259-64.

53. Bhagyasri1 Y, Lavakumar V, Divya SMS, Ashok KCK. An overview on anti-inflammatory activity of Indian herbal plants. International Journal of Pharmaceutical Sciences and Nanotechnology. 2015;4(1):1-9.

54. Saha C, Hegde P, Friboulet A, Bayry J, Kaveri SV. Viscum album - mediated COX-2 inhibition implicates destabilization of COX-2 mRNA. PLoS One 2015; 10(2):e0114965

55. Roy SP, Niranjan CM, Jyothi TM, Shankrayya MM, Vishawanath KM, Prabhu K, et al. Antiulcer and anti-inflammatory activity of aerial parts Enicostemma littorale Blume. Pharmacology. 2010;2(4):369-73.

56. Garg VKR, Jain M, Sharma PKR, Garg G. Anti inflammatory activity of Spinacia oleracea. International Journal of Pharma Professionals Research. 2010;1(1):1-4.

57. Alcaraz MJ, Jimenez MJ. Flavonoids as anti-inflammatory agents. Fitoterapia. 1988;59:25-38

58. Robak J, Gryglewski RJ. Bioactivity of flavonoids. Polish Journal of Pharmacology. 1996;48(6):555-64.

59. Chatterjee A, Sen B, Das S, Chatterjee TK. Anti-inflammatory and analgesic activity of methanolic extract of Medicinal Plant Rhodiola rosea I. Rhizomes. International Journal of Pharmaceutical Sciences Review and Research 2015;4(2):1-8

60. Amin B, Rachida A. Anti-inflammatory activity Citrus essence (C. Sinensisand C. aurantium) Local to Chlef Region (Algeria): In vivo study. Journal of Biomolecular Research and Therapeutics. 2015;4:126.

61. Okwu DE. Citrus fruits: A rich source of phytochemicals and their roles in human health. International Journal of Chemical Sciences. 2008;6:451-71.

62. Lee EJ, Kim DI, Kim WJ, Moon SK. Naringin inhibits matrix metalloproteinase-9 expression and AKT phosphorylation in tumor necrosis factor-alpha-induced vascular smooth muscle cells. Molecular Nutrition and Food Research. 2009;53(12):1582-91.

63. Vanu MR, Palanivelu S, Panchanatham S. Immunomodulatory and antiinflammatory effects of Semecarpus anacardium Linn. Nut milk extract in experimental inflammatory conditions. Biologica and Pharmaceutical Bulletin. 2006;29(4):693-700

64. Othman RA, Moghadasian $\mathrm{MH}$. Beyond cholesterol-lowering effects of plant sterols: Clinical and experimental evidence of anti-inflammatory properties. Nutrition Reviews. 2011;69(7):371-82.

65. Kam PC, Liew S. Traditional Chinese herbal medicine and anaesthesia. Anaesthesia 2002;57(11):1083-9.

66. Andrikopoulos NK, Kaloria AC, Assimopolou NA. Biological activity of some naturally occurring resins, gums and pigments against in vitro LDL oxidation. Phytotherapy Research. 2003;7(5):501-7.

\section{SUMMARY}

- The present study was aimed to evaluate the anti-inflammatory and analgesic potentials in peels of some commercially grown Citrus fruits of South India viz, Lime. Orange, Sour Orange, Pomello and Citron.

- The anti-inflammatory activity of extracts at 250 and $500 \mathrm{mg} / \mathrm{Kg}$ body weight concentrations were assessed by in vivo Carrageenan induced rat paw edema model and in vitro HRBC membrane stabilization assay whereas Tail immersion and Hot plate methods have been used to evaluate their analgesic property.

- From the results it was evident that all Citrus fruits have prominent activity in terms of parameters assessed in a dose dependent manner and are more effective in the later phase. The study thus documents that Citrus peels are good sources of anti-inflammatory and anti-nociceptive agents. 